\title{
Patient autonomy or patient confusion?
}

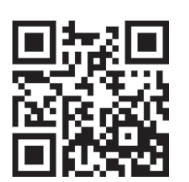

A couple of weekends ago a friend, Richard, popped in for a cup of tea - a very fit, active septuagenarian who rides the Cape Argus Pick n Pay Cycle Tour every year and has recently started running. A few years ago he had a triple bypass. At the time, his cardiologist told him that, 'From today, you become a vegetarian ... ' According to Richard, the cardiologist told him to cut out eggs, butter, red meat and any source of saturated fats from his diet; standard advice that we have all given at some stage in our careers. Richard's problem, though, was this: 'Now' he says, 'I am told that margarine is actually bad for me, eggs are fine and there are even people saying that it is OK to eat saturated fats - who is right? What do I do?'

Scanning the popular medical press over the past few months would only have added to Richard's confusion - with headlines such as: 'New analysis suggests whole diet approach to lower cardiovascular risk has more evidence than low-fat diets'; ${ }^{[1]}$ 'Butter is bad - a myth we've been fed by the "healthy eating" industry. ${ }^{[2]} \mathrm{I}$ would imagine that many doctors are confused - just think how your patients must be feeling.

Along with the furore about possibly modifying 'healthy eating' guidelines (never mind the heated debate over fats v. carbohydrates), we have conflicting advice on the globally popular, bestselling cholesterol drugs - the statins - from: 'Taking statins to lower cholesterol? New guidelines provide opportunity to discuss options with your doctor' - Mayo Clinic; ${ }^{[3]}$ 'Low-dose statins good option for some heart patients, study finds' - Medical Xpress; ${ }^{[4]}$ to the confusing alternative: 'Cholesterol drug statins should be given to millions more, [National Health Service (NHS)] guidance says' - The Guardian. ${ }^{[5]}$

We live in an era of patient autonomy; the idea being to involve our patients more in their care. All well and good, and certainly better than the paternalistic attitude that was prevalent a few decades ago, but what is it that we are expecting patients to do?

The Mayo Clinic, ${ }^{[3]}$ based on a commentary by three of their physicians published recently in JAMA ${ }^{[6]}$ on the 2013 American College of Cardiology and American Medical Association cardiovascular guidelines, ${ }^{[7]}$ informs the the reader - assumed to be a layperson - that 'clinicians and patients should use shared decision-making to select individualised treatments based on the new guidelines to prevent cardiovascular disease'.

They add, 'Shared decision-making is a collaborative process that allows patients and their clinicians to make health care decisions together, taking into account the best scientific evidence available, as well as the patient's values and preferences.' The new guidelines recommend that anyone with a '10-year cardiovascular risk of $7.5 \%$ or higher' is offered statins. But, the article goes on to say, '[commentator] Dr Montori cautions that the risk threshold established by the guideline panel is somewhat arbitrary. Instead he recommends that patients and their clinicians use a decision-making tool to discuss the risks and benefits of treatment with statins'.

This same learned gentleman adds that rather than routinely prescribing statins to the millions of adults who have at least a $7.5 \%$ risk of having a heart attack or stroke within 10 years, clinicians and patients should discuss the potential harms and burdens of statins to arrive at a decision that 'reflects the existing research and the values and context of each patient'. He goes on to say - very tellingly in my opinion - ' ... we move the decision-making from the scientist to the patient ....

Conversely, the article in The Guardian, ${ }^{[5]}$ arguably read by fairly well-educated people, explains that new NHS guidance says that everyone who has only a low risk of heart disease or stroke should be offered statins, already taken by some 7 million people in England. The National Institute for Health and Care Excellence (NICE), itself rather a paternalistic outfit, is now telling British GPs that they should prescribe - not offer - statins to all those with a $10 \%$ risk of heart disease and stroke, dropped from the previous threshold of $20 \%$, and different again from the US threshold of 7.5\% ${ }^{[8]}$

Many doctors find it difficult to interpret guidelines - all based on relatively complex statistical analyses derived from drug trials, many of which used different methods of analysis and all of which talk about percentage risk, relative risk, confidence limits, number needed to treat, hazard ratios, etc. - which, with the best will in the

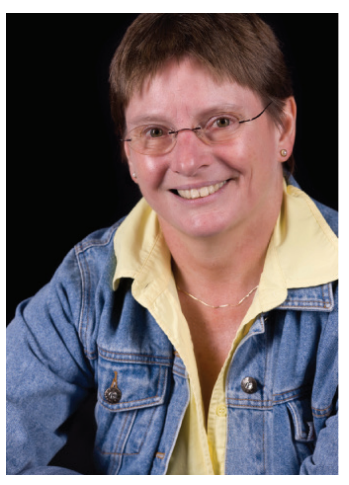
world, most of us cannot interpret easily. Yet, we are asking our patients to make decisions 'in consultation' based on tools developed using these statistics?

In my opinion, we need to think again about exactly what patient autonomy means and make sure that we don't simply offer confusion.

\section{Bridget Farham}

Deputy Editor

ugqirha@iafrica.com

1. Elsevier Press Release. New analysis suggests whole diet approach to lower cardiovascular risk has more evidence than low-fat diets. Philadelphia, PA. 5 February 2014. http://www.elsevier.com/about/pressreleases/research-and-journals/new-analysis-suggests-whole-diet-approach-to-lower-cardiovascularrisk-has-more-evidence-than-low-fat-diets\#sthash.KRXvrqN3.dpuf (accessed 12 February 2014).

2. Blythman J. Butter is bad - a myth we've been fed by the "healthy eating' industry. The Guardian. 23 October 2013. http://www.theguardian.com/commentisfree/2013/oct/23/butter-bad-saturated-fat-
Octhman J healthy-eating-industry (accessed 12 February 2014).

3. Plutowski S. Taking statins to lower cholesterol? New guidelines provide opportunity to discuss options with your doctor. Mayo Clinic News Network. 4 February 2014. http://newsnetwork.mayoclinic. org/discussion/taking-statins-to-lower-cholesterol-new-guidelines-provide-opportunity-to-discussoptions-with-your- (accessed 12 February 2014).

4. Brophy Marcus M, HealthDay. Low-dose statins good option for some heart patients, study finds. Medical Xpress. 10 February 2014. http://medicalxpress.com/news/2014-02-low-dose-statins-goodoption-heart.html (accessed 12 February 2014).

5. Boseley S. Cholesterol drug statins should be given to millions more, NHS guidance says. The Guardian. 12 February 2014. http://www.theguardian.com/society/2014/feb/12/cholesterol-drugstatins-offered-millions-more-nhs-guidance (accessed 12 February 2014).

6. Montori VM, Brito JP, Murad MH. The optimal practice of evidence-based medicine: Incorporating patient preferences in practice guidelines. JAMA 2013;310(23):2503-2504. [http://dx.doi.org/10.1001/ jama.2013.281422]

7. Stone NJ, Robinson J, Lichtenstein AH. 2013 ACC/AHA Guideline on the Treatment of Blood Cholesterol to Reduce Atherosclerotic Cardiovascular Risk in Adults: A Report of the American College of Cardiology/American Heart Association Task Force on Practice Guidelines. Circulation 2014 (in press). [http://dx.doi.org/10.1161/01.cir.0000437738.63853.7a]

8. NICE. Lipid modification: Cardiovascular risk assessment and the modification of blood lipids for the primary and secondary prevention of cardiovascular disease. http://guidance.nice.org.uk/CG/ WaveR/123 (accessed 12 February 2014).

S Afr Med J 2014;104(3):152. DOI:10.7196/SAMJ.8060 